ANUVA Volume 2 (3): 299-305, 2018

Copyright (C2018, ISSN: 2598-3040 online

Available Online at: http://ejournal.undip.ac.id/index.php/anuva

\title{
Mempersiapkan Pustakawan Multitasking untuk Melayani Pemustaka Generasi Z
}

\author{
Roro Isyawati Permata Ganggi*)

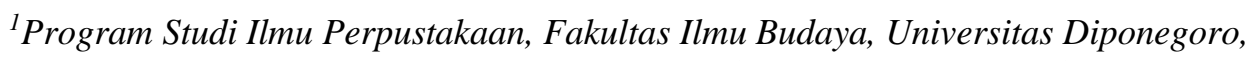 \\ Jl. Prof. Soedarto, SH, Kampus Undip Tembalang, Semarang, Indonesia \\ *) Korespondensi: isya.ganggi@gmail.com
}

\begin{abstract}
[Title: Preparing Librarians Multitasking to serve Generation Z] Ranganathan's five laws mention that the library is a growing organization, not only applies to the library but also for librarians. A librarian must have dynamic in providing service to the user. Characters of the user that are served by the librarian has been changed. A user who later became the library market segmentation is a user of the $Z$ generation. User of $Z$ generation is users who want real-time information and have a great interest in the use of social media. Librarians in serving the $Z$ generation sued for can be a multitasker, because library currently does not just focus solely on conventional service but also on digital-based service. Digital-based service is a service of library which accessible nonstop. To make it digital-based service happen are needed a multitasking librarian who understand about literacy. Multitasking librarian need to understand literacy media, digital literacy, information literacy, visual literacy, global literacy, cultural literacy, and biliteracy in an effort to provide maximum service to the user $Z$ generation
\end{abstract}

Keywords: multitasking librarians; Z generation; literate person

\begin{abstract}
Abstrak
Hukum ke lima Ranganathan menyebutkan bahwa perpustakaan merupakan organisasi yang berkembang, tidak hanya berlaku bagi perpustakaan tetapi juga bagi pustakawan. Hal ini dikarenakan maju tidaknya suatu perpustakaan tergantung pada pustakawannya. Pustakawan dituntut dinamis dalam memberikan pelayanan kepada pemustaka. Seiring perkembangan zaman pun pemustaka yang dilayani oleh pustakawan mengalami perubahan karakter. Pemustaka yang nantinya menjadi segmentasi pasar perpustakaan adalah pemustaka dari golongan Generasi $\mathrm{Z}$. Pemustaka Generasi $\mathrm{Z}$ ini merupakan pemustaka yang menginginkan informasi real-time dan memiliki minat yang besar dalam penggunaan media sosial. Pustakawan dalam melayani generasi $\mathrm{Z}$ dituntut untuk dapat menjadi multitasker, karena perpustakaan saat ini tidak hanya berfokus pada layanan secara konvensional tetapi juga layanan berbasis digital yang mampu diakses nonstop. Pustakawan Multitasking perlu memahami literasi media, literasi digital, literasi informasi, literasi visual, literasi global, literasi budaya, dan biliteracy dalam upaya memberikan pelayanan yang maksimal kepada pemustaka Generasi Z.
\end{abstract}

Kata kunci: pustakawan multitasking; Generasi Z; literate person

\section{Pendahuluan}

Hukum Ranganathan menyebutkan bahwa perpustakaan merupakan organisasi yang berkembang. Hukum tersebut selaras dengan keadaan saat ini dimana perpustakaan telah bertransformasi mengikuti perkembangan zaman. Transformasi perpustakaan dapat dilihat dari munculnya jenis perpustakaan mulai dari perpustakaan yang memiliki gedung, perpustakaan hybrid, dan perpustakaan digital. Hukum Ranganathan tersebut tidak hanya berlaku bagi perpustakaan saja, tetapi juga untuk pustakawan, sebagai profesi yang berkaitan erat dengan perpustakaan. 
Pustakawan dituntut untuk selalu mengembangkan diri karena tuntutan pemustaka yang semakin beragam. Tuntutan pemustaka banyak dipengaruhi oleh kemajuan teknologi. Tuntutan pemustaka saat ini lebih kepada one stop service. Layanan yang diinginkan pemustaka tidak hanya berupa layanan untuk akses informasi cepat tetapi juga layanan untuk dapat berkomunikasi dengan pustakawan meskipun tidak bertatap muka secara langsung.

Komunikasi secara dua arah dalam layanan digital merupakan layanan yang belum banyak diterapkan oleh perpustakaan di Indonesia. Data Badan Pusat Statistik menunjukkan bahwa penduduk Indonesia pada tahun 2017 yang berusia 0-19 tahun sebesar 35\% (Badan Pusat Statistik, 2013: 49-52). Rentang usia antara 0-19 tahun lebih sering disebut sebagai generasi Z. Generasi Z merupakan generasi yang lahir pada era teknologi komunikasi informasi dimana mereka menuntut layanan yang serba cepat dengan tetap memperhatikan azaz komunikasi dua arah. Kebutuhan Generasi Z akan komunikasi dua arah terlihat dari banyaknya pengguna media sosial di usia ini.

Pemustaka di perpustakaan perguruan tinggi pada akhirnya akan banyak didominasi oleh generasi Z. Generasi ini merupakan generasi pop culture yang selalu berubah-ubah demi mengikuti perkembangan zaman. Generasi yang lahir dalam pop culture cenderung mengabaikan tradisi dan memilih untuk mengikuti tren yang sedang berkembang. Oleh karena itu pustakawan harus mampu menjadi pustakawan multitasking demi memenuhi tuntutan pemustaka yang digolongkan dalam generasi ini (generasi Z).

\section{Teori Generasi}

Manusia merupakan salah satu objek penelitian yang tidak habis dibahas. Hal ini dapat dibuktikan dari banyaknya penggolongan manusia oleh para ahli. Penggolongan manusia yang paling banyak dibicarakan dewasa ini adalah teori generasi X, Y dan Z. Teori Generasi X, Y, dan Z banyak digunakan untuk menggambarkan perubahan perilaku generasi yang dipengaruhi oleh kemajuan teknologi. Teori Generasi X, Y, dan Z ini sebenarnya adalah penggolongan manusia berdasarkan tahun kelahirannya yang dilakukan oleh Don Tapscott. Penggolongan manusia oleh Tapscott (2009: 11-21) dibagi menjadi lima, yaitu:

1. Pre Baby Boom (Golongan yang lahir sebelum tahun 1945)

2. The Baby Boom (Golongan yang lahir pada 1946 -1964)

3. The Baby Bust atau Generasi X (Golongan yang lahir pada 1965 - 1976)

4. The Echo of the Baby Boom atau Generasi Y (Golongan yang lahir pada 1977 -1997)

5. Generation Net atau Generasi Z (Golongan yang lahir pada 1998 - Saat ini).

Berdasarkan data dari proyeksi Badan Pusat Statistik (2013: 49-52) persentase penduduk Indonesia pada tahun 2017 dalam golongan Pre Baby Boom sebanyak 3\%, The Baby Boom sebanyak 16\%, Generasi X sebanyak 14\%, Generasi Z sebanyak 32\%, dan Generasi Z sebanyak 35\%. Data dari Badan Pusat Statistik tersebut menunjukkan bahwa penduduk Indonesia di dominasi oleh Generasi Z atau 
penduduk dengan rentang umur dibawah 19 tahun, sebanyak $35 \%$. Generasi Z ini yang nantinya akan menjadi segmentasi pengguna perpustakaan.

Generasi $\mathrm{Z}$ merupakan generasi yang lahir pada masa informasi. Generasi ini sudah mengenal teknologi pada saat mereka lahir. Karakteristik generasi $\mathrm{Z}$ adalah saat ini juga, realisme, generasi berpendidikan, dan pengguna gadget yang mahir (Codrington, 2008). Generasi Z merupakan generasi yang melek teknologi dan banyak memiliki ketertarikan terhadap media sosial. Generasi Z menjadikan media sosial sebagai sarana komunikasi. Basis teknologi yang dimiliki oleh generasi ini menuntut segala sesuatunya serba cepat dan multitasking, sehingga tidak jarang generasi ini disebut juga "Generasi Google".

\section{Karakteristik Generasi Z sebagai Pemustaka}

Robert Wendover menjelaskan bahwa setiap generasi baru adalah produk yang dipengaruhi oleh serapan era yang sedang berlangsung (2005: 36). Generasi Z merupakan generasi yang merasa nyaman dengan penggunaan teknologi semenjak munculnya keberadaan laptop, tablet, dan smartphone. Generasi ini sangat familiar dengan gadget berteknologi tinggi. Mereka sudah mengenal teknologi semenjak mereka lahir. Wallace, Tolley-Stokes, dan Estep (2011: 26) merumuskan hal-hal yang mempengaruhi pencarian informasi generasi ini:

1. Fokus secara global; Generasi $\mathrm{Z}$ mulai memperhatikan isu-isu global yang terjadi di dunia. Generasi ini cenderung mengikuti trend yang ada di luar negeri.

2. Keberagaman; Adanya teknologi membuat generasi ini mampu menerima keberagaman yang ada. Hal ini terjadi karena saat ini ruang lingkup sosial mereka dapat meluas tanpa ada hambatan jarak dan waktu.

3. Cyberliterate; Merupakan kemampuan untuk melek terhadap teknologi. Tidak terbatas hanya pada pemahaman terhadap cara menggunakan suatu teknologi tetapi juga pada pemahaman bagaimana arus suatu informasi bekerja dan bagaimana dapat berinteraksi terhadap informasi tersebut.

4. Kolaboratif; Generasi ini mampu menggabungkan beberapa informasi dan menjadikannya informasi baru. Mereka sangat kreatif dalam menanggapi suatu informasi.

5. Multitasking; Generasi ini mampu mengerjakan beberapa pekerjaan sekaligus, seperti mendengarkan musik sambil mengerjakan tugas.

6. Teamwork; Penggunaan media sosial oleh generasi ini membuat Generasi Z senang bekerja secara teamwork.

7. Teknologi; Karena terlahir di era teknologi maka adanya perkembangan teknologi mempengaruhi pencarian generasi ini. Mereka banyak menggunakan teknologi mesin pencarian untuk mencari sesuatu. 
Pemustaka dalam generasi ini cenderung mencari informasi yang bersifat langsung (real time). Hal ini membuat pemustaka menjadi update akan informasi yanga ada. Pemustaka pada Generasi Z tidak mempermasalahkan media informasi. Generasi $\mathrm{Z}$ mampu menggunakan berbagai media yang ada untuk memenuhi kebutuhan informasi mereka, meskipun mereka lebih cenderung menggunakan jenis media digital. Generasi jenis ini juga menyukai penggunaan instant messaging dan sosial media. Penggunaan sosial media bagi generasi ini selain untuk berkomunikasi tetapi juga sebagai salah satu media penyebaran informasi.

Pencarian utama oleh generasi ini adalah menggunakan mesin pencarian atau search engine. Hal ini mengacu karena mesin pencari mampu menampilkan informasi dalam jumlah banyak hanya dalam hitungan detik. Mesin pencarian yang sering digunakan adalah Google, generasi ini berfokus pada ranking hasil pencarian dari Google. Baker dan Evans (2016: 220) mengatakan bahwa generasi ini hanya mengandalkan halaman utama Google karena mereka tidak menyukai browsing. Generasi ini memiliki ketergantungan yang tinggi terhadap akses internet. Mereka menginginkan untuk selalu dapat terkoneksi dengan kecepatan yang tinggi. Generasi $\mathrm{Z}$ merupakan pemustaka yang menginginkan akses informasi nonstop melalui gadget mereka. (Baker dan Evans, 2016: 220)

\section{Pustakawan Multitasking}

Pustakawan oleh kebanyakan masyarakat masih dipandang secara konvensional, dimana pustakawan merupakan profesi yang terbatas hanya pada menyusun buku ke rak dan menjaga perpustakaan. Stereotipe ini masih banyak dipercayai meskipun tugas pokok pustakawan tidak hanya menyusun buku dan menjaga perpustakaan. Masuknya teknologi ke dalam perpustakaan membuat pustakawan mencoba mensinergikan teknologi dengan perpustakaan. Pustakawan pada era digital saat ini memiliki lebih banyak tantangan dibandingkan dengan pustakawan pada masa sebelumnya.

Pustakawan dalam memberikan pelayanan kepada Generasi $\mathrm{Z}$ dihadapkan pada situasi yang unik dimana:

1. Dalam struktur hierarki dalam perpustakaan, pustakawan diminta dapat mengembangkan manajemen partisipatif yang berarti menyamakan persepsi antara pustakawan junior dan pustakawan senior. Hal ini dikarenakan sering kali terjadi jarak antara perspektif pustakawan junior dan pustakawan senior dalam memandang suatu permasalahan.

2. Perubahan teknologi membutuhkan kemampuan baru dan sudut pandang baru dalam layanan perpustakaan. Kemajuan teknologi menimbulkan kesan tentang bahwa Generasi Z secara kualitas lebih menguasai teknologi.

3. Generasi $\mathrm{Z}$ merupakan tantangan baru bagi perpustakaan. Pustakawan dituntut supaya dapat menjadi mesin pencari otomatis seperti Google. Tuntutan tersebut tersebut relevan dengan era dimana saat ini informasi dapat didapat dengan mudah, hanya saja relevansinya masih banyak dipertanyakan. 
4. Literasi informasi merupakan kemampuan wajib untuk dapat melayani pemustaka yang berasal dari Generasi Z. Pustakawan selain harus memiliki literasi informasi juga harus mampu untuk menularkan literasi informasi tersebut kepada pemustaka.

5. Manajemen keuangan, teknologi yang semakin berkembang membuat perpustakaan perlu membuat anggaran ekstra untuk membeli peralatan teknologi yang baru. Jika pustakawan tidak memiliki keahlian dalam manajemen keuangan tentu perpustakaan akan kesulitan membuat skala prioritas untuk mengatur keuangan mereka.

6. Mampu menggunakan sosial media. Generasi $\mathrm{Z}$ merupakan generasi yang aktif dalam bersosial media. Pustakawan pun diharapkan mampu menggunakan sosial media untuk menciptakan komunikasi dua arah antara pemustaka dengan pustakawan di dunia maya.

Pustakawan dituntut untuk dapat bekerja multitasking, seperti telah disinggung bahwa generasi $\mathrm{Z}$ merupakan generasi multitasking. Hal ini membuat pustakawan harus mampu mengimbangi ritme dari para pemustakanya. Multitasking sendiri diartikan sebagai kemampuan untuk melakukan beberapa pekerjaan dalam satu waktu (Reitz, 2014). Multitasking dibedakan menjadi dua oleh Wallis (2010), yaitu:

1. Macro-multitasking: menyelesaikan beberapa proyek, perjanjian, atau tugas dengan waktu yang hampir berbarengan.

2. Micro-multitasking: multitasking yang dilakukan dengan cara mengalihkan perhatian di saat melakukan pekerjaan untuk melakukan pekerjaan lain, seperti menerima telepon, mendengarkan musik, mengobrol dengan seseorang.

Multitasking yang dapat dilakukan oleh pustakawan, adalah dengan melakukan pekerjaan rutin mereka tetapi tetap menyempatkan diri untuk menanggapi pemustaka di dunia maya. Hal ini dapat dilakukan untuk mengikuti ritme pemustaka. Sayangnya, kemampuan melakukan pekerjaan secara multitasking memerlukan latihan yang cukup panjang. Pustakawan multitasking dapat memanfaatkan waktu luangnya untuk memajukan layanan perpustakaan. Multitasking memungkinkan pustakawan untuk bekerja cepat dan efisien.

Literasi merupakan salah satu keterampilan yang dapat dimanfaatkan oleh pustakawan sebagai dukungan untuk menjadi pustakawan multitasking. Literasi oleh Koltay (2011) dibedakan menjadi tiga jenis, yaitu: (1) Literasi Media; (2) Literasi Informasi; (3) Literasi Digital. Seorang pustakawan dalam melayani pemustaka generasi $\mathrm{Z}$ perlu memperluas jangkauan literasinya. Literasi yang dimiliki oleh seorang pustakawan tidak hanya terbatas oleh tiga jenis literasi saja, namun harus ditambahi dengan literasi lain yang mendukung peran pustakawan dalam melayani Generasi Z. Literasi yang perlu dimiliki oleh seorang pustakawan, diantaranya:

\section{Literasi Media}

Literasi Media merupakan penguasaan seseorang untuk berfikir secara kritis dan kreatif dalam memahami media masa. Seorang pustakawan perlu menguasai literasi media karena pada saat ini 
media massa berkembang sangat pesat. Pustakawan merupakan garda depan informasi, tentu perlu untuk dapat menelaah secara kritis informasi yang tersebar di media massa.

\section{Literasi Budaya}

Literasi budaya merupakan kemampuan untuk memahami dan mengapresiasi keberagaman dalam adat istiadat, norma, dan kepercayaan untuk baik bagi kebudayaan sendiri maupun kebudayaan lainnya. Kedepannya pemustaka yang dilayani tidak hanya terbatas pada kebudayaan yang sama tetapi juga lintas budaya.

\section{Literasi Informasi}

Literasi informasi merupakan tipe informasi yang paling sering digunakan dalam perpustakaan. Literasi ini merupakan suatu kemampuan untuk mengetahui kebutuhan informasi, kemampuan mengidentifikasi, mencari, mengevaluasi dan secara efektif menggunakan informasi tersebut.

\section{Literasi Digital}

Literasi digital merupakan kewaspadaan, sikap, dan kemampuan seseorang menggunakan peralatan digital sebagaimana mestinya dan mengidentifikasi, mengakses, memanajemen, mengintegrasi, mengevaluasi, menganalisis dan mensistesis sumber daya digital, mengkontruksi pengetahuan baru, serta mengkomunikasikannya dengan yang lain dengan tujuan mengkontruksi aksi sosial dan merefleksikan prosesnya. (Martin, 2006: 19). Generasi Z merupakan generasi yang lahir pada era digital, sehingga penguasaan literasi digital oleh pustakawan merupakan hal wajib. Saat ini perpustakaan sudah banyak mengintegrasikan bahan pustaka tercetak maupun digital. Beragamnya sumberdaya digital pun membuat pustakawan harus mampu memilah dan memilih mana yang baik bagi pemustakanya.

\section{Literasi Visual}

Literasi visual merupakan kemampuan untuk memahami dan memproduksi pesan visual. Generasi Z merupakan generasi yang mengalami pergeseran dari kertas menuju pixel. Hal ini terbukti adanya meme (pesan melalui gambar) yang banyak beredar di dunia maya. Generasi Z lebih menyenangi mengirimkan meme atau emoticon dalam komunikasi mereka dibandingkan mengirim pesan berupa kata-kata.

\section{Literasi Global}

Literasi global didefinisikan sebagai pemahaman terhadap manusia dan negaranya serta memiliki kemampuan untuk berinteraksi dan berkolaborasi dengan lintas budaya. Adanya Masyarakat Ekonomi ASEAN (MEA) memungkinkan ada banyak pemustaka yang berasal dari luar negeri. Hal ini tentu membutuhkan literasi global untuk dapat memahami pemustaka.

\section{Biliteracy}

Biliteracy atau yang lebih dikenal dengan literasi bahasa adalah penguasaan terhadap dua bahasa atau lebih. Mengingat mudahnya informasi didapatkan dan beragamnya pemustaka yang dilayani, seorang pustakawan perlu menguasai lebih dari satu bahasa. Pemahaman terhadap beberapa bahasa akan 
memudahkan pustakawan dalam memberikan layanan dan dalam mengolah informasi sebelum dilayankan.

\section{Penutup}

Generasi Z merupakan salah satu pemustaka yang menuntut adanya kedinamisan di perpustakaan terutama dalam hal teknologi. Generasi ini memiliki basis teknologi yang kuat, pengguna media sosia, dan merupakan Generasi Google. Hal ini tentu mengharuskan pustakawan untuk menciptakan inovasi baru terhadap layanan di perpustakaan. Pustakawan dituntut untuk menjadi seorang pustakawan multitasking yang mampu mengerjakan beberapa pekerjaan dalam satu waktu. Mempersiapkan seorang pustakawan yang memiliki kemampuan multitasking tidaklah mudah. Pustakawan multitasking perlu menguasai beberapa jenis literasi demi terciptanya pelayanan yang dinamis untuk menyambut para Generasi $\mathrm{Z}$ di perpustakaan. Literasi yang harus dimiliki oleh seorang pustakawan diantaranya adalah: literasi media, literasi budaya, literasi informasi, literasi digital, literasi visual, literasi global, dan biliteracy.

\section{Daftar Pustaka}

Badan Pusat Statistik. 2013. Proyeksi Penduduk Indonesia 2010-2035. Jakarta: Badan Pusat Statistik.

Baker, David dan Wendy Evans. 2016. Digital Information Strategies: From Applications and Content to Libraries and People. Waltham: Chandos Publishing.

Codrington, Graeme. 2008. Detailed Introduction to Generational Theory. Diunduh dari http://www.tommorrowtoday.uk.com/articles/pdf/TomorrowToday detailed_intro to Generations. pdf

Gordon, Rachel Singer. 2006. Nextgen Librarian's Survival Guide. Medford: Information Today, Inc.

Koltay, Tibor. 2011. The Media and The Literacies: Media Literacy, Information Literacy, Digital Literacy. Diunduh dari http://mcs.sagepub.com/content/33/2/211

Martin, Allan and Dan Madigan. 2006. Literacies for Digital Age. London: Facet.

Reitz, Joan M. 2014. Online Dictionary and Information Science. Diunduh dari http://www.abcclio.com/ODLIS/odlis_m.aspx

Tapscott, Don. 2009. Grown Up Digital: How The Net Generation is Changing Your World. New York: Mc Graw Hill.

Wallace, Martin K; Rebecca Tolley-Stokes; Erik Sean Estep.2011. The Generation X Librarian: Essays on Leadership, Technology, Pop Culture, Social Responsibility and Proffesional Identity. Diunduh dari http://e-resources.perpusnas.go.id:2080/lib/perpusnas/reader.action?docID=10467660\&ppg=6

Wallis, Claudia. 2010. The Impacts of Media Multitasking on Children's Learning \& Development. Diunduh dari https://multitasking.stanford.edu/MM_FinalReport_030510.pdf

Wendover, Robert W. 2005. From Ricky \& Lucy to Beavis \& Butthead: Managing The New Workforce. Colorado: The Center for Generational Studies, Inc. 